\title{
Transperineal ultrasonography in perianal Crohn disease: A valuable imaging modality
}

\author{
Emily K Wright $M D^{1,2}$, Kerri L Novak MD¹, Cathy Lu MD¹, Remo Panaccione MD ${ }^{1}$, \\ Subrata Ghosh MD FCAHS 1 , Stephanie R Wilson MD ${ }^{1,3}$
}

\begin{abstract}
EK Wright, KL Novak, C Lu, R Panaccione, S Ghosh, SR Wilson. Transperineal ultrasonography in perianal Crohn disease: A valuable imaging modality. Can J Gastroenterol Hepatol 2015;29(8):445-447.
\end{abstract}

Aims of treatment for Crohn disease have moved beyond the resolution of clinical symptoms to objective end points including endoscopic and radiological normality. Regular re-evaluation of disease status to safely, readily and reliably detect the presence of inflammation and complications is paramount. Improvements in sonographic technology over recent years have facilitated a growing enthusiasm among radiologists and gastroenterologists in the use of ultrasound for the assessment of inflammatory bowel disease. Transabdominal intestinal ultrasound is accurate, affordable and safe for the assessment of luminal inflammation and complications in Crohn disease, and can be performed with or without the use of intravenous contrast enhancement. Perianal fistulizing disease is a common, complex and often treatment-refractory complication of Crohn disease, which requires regular radiological monitoring. Endoanal ultrasound is invasive, uncomfortable and yields limited assessment of the perineal region. Although magnetic resonance imaging of the pelvis is established, timely access may be a problem. Transperineal ultrasound has been described in small studies, and is an accurate, painless and cost-effective method for documenting perianal fluid collections, fistulas and sinus tracts. In the present article, the authors review the literature regarding perineal ultrasound for the assessment of perianal Crohn disease and use case examples to illustrate its clinical utility.

\section{L'échographie transpérinéale en cas de maladie de Crohn périanale : un précieux mode d'imagerie}

Les objectifs du traitement de la maladie de Crohn ne se limitent plus à la résolution des symptômes cliniques, mais visent désormais des paramètres objectifs, y compris la normalité endoscopique et radiologique. Il est essentiel de réévaluer régulièrement l'état de la maladie pour déceler rapidement, de manière sécuritaire et fiable, la présence d'inflammation et de complications. Ces dernières années, les améliorations à la technologie échographique ont favorisé un enthousiasme croissant de la part des radiologues et des gastroentérologues envers l'utilisation de l'échographie pour évaluer les maladies inflammatoires de l'intestin. L'échographie intestinale transabdominale, qui est précise, peu coûteuse et sécuritaire pour évaluer l'inflammation et les complications intracavitaires en cas de maladie de Crohn, peut être effectuée avec ou sans agent de contraste. Les fistules périanales sont une complication courante, complexe et souvent réfractaire au traitement, qui exigent une surveillance radiologique régulière. L'échographie endoanale est invasive, désagréable et permet peu d'évaluer la région périnéale. Même si l'imagerie par résonance magnétique du bassin est établie, son accès rapide peut être problématique. L'échographie transpérinéale, décrite dans de petites études, est précise, indolore et rentable pour vérifier l'accumulation de liquides périnéaux, les fistules et les voies sinusales. Dans le présent article, les auteurs examinent les publications scientifiques sur l'échographie périnéale pour évaluer la maladie de Crohn périnéale. Ils utilisent des exemples de cas pour en illustrer l'utilité clinique.

Key Words: Crohn disease; Inflammatory bowel disease; Perianal fistula; Ultrasound

Derianal Crohn disease is a common, important, complex and dis-
tressing complication of Crohn disease (1,2). Even with regular
anti-tumour necrosis factor therapy, long-term healing rates are poor
(3). Despite closure of draining external orifices, deep fistula tracks may
persist, placing patients at risk for further complications (4). Regular
assessment with imaging is, therefore, important as part of comprehen-
sive patient care. Magnetic resonance imaging (MRI) of the pelvis has
been described extensively for the assessment of perianal Crohn disease.
It offers good soft tissue discrimination and enables multiplanar image
acquisition without radiation hazard; however, cost and timely access to
this resource have limited frequent use for some patients. Endoanal
ultrasound has also been described for the assessment of perianal Crohn
disease, but is invasive, often poorly tolerated in the context of active
perianal sepsis and impossible to perform if anal stenosis is present. With
this technique, perineal views are incomplete and pathological changes
expanding to the gluteal region cannot be assessed.
Transperineal ultrasound has been described as a simple and painless
method to examine perianal pathology and provides imaging quality comparable with both endoanal ultrasound and MRI $(5,6)$. For the assessment of perianal Crohn disease, including abscess collections, fistulas and sinus tracts, transperineal ultrasound has been validated by several groups $(7-10)$.

Using case examples, we illustrate the utility of transperineal ultrasound in the assessment of patients with perianal Crohn disease. We hope to advocate for its wider use in Canadian practice. We summarize the clinical studies to date evaluating this imaging modality in this population.

\section{CASE 1}

A 26-year-old woman with ileocolonic and perianal Crohn disease undergoing therapy with adalimumab and methotrexate was referred for investigation of increasing perianal pain. Transperineal ultrasound was performed. Figure 1 shows the level of the low anal canal. There are two low internal openings at one o'clock and six o'clock. The tract at one o'clock (Figure $1[\mathrm{~A}]$ ) was observed on the left anterolateral wall; from this, there is a transphincteric tract that runs laterally to the

\footnotetext{
${ }^{1}$ Department of Medicine, Division of Gastroenterology, University of Calgary, Foothills Medical Centre, Calgary, Alberta; ${ }^{2}$ Department of

Gastroenterology, St Vincent's Hospital and The University of Melbourne, Melbourne, Victoria, Australia; ${ }^{3}$ Department of Diagnostic Imaging,

University of Calgary, Foothills Medical Centre, Calgary, Alberta

Correspondence: Dr Stephanie R Wilson, Diagnostic Imaging, Foothills Medical Centre, Calgary, Alberta T2N 4J8.

Telephone 403-944-2680, fax 403-944-2790, e-mail emily.wright@svha.org.au

Received for publication April 6, 2015. Accepted April 7, 2015
} 


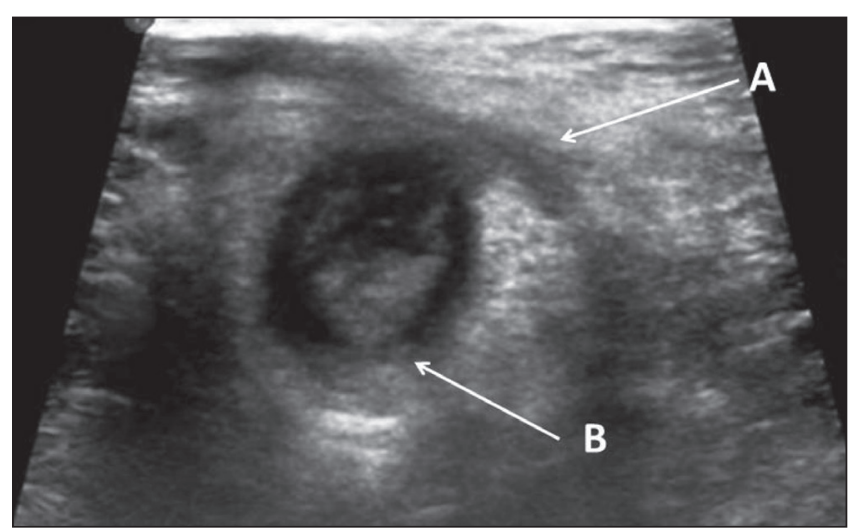

Figure 1) Transverse view of the anal canal showing a transphincteric hookshaped fistula (A), which has an internal opening on the left anterolateral wall of the anal canal at one o'clock. Its external opening on the skin of the left anterior perineum is not shown on this image. Arrow (B) indicates a small second internal opening directly posterior at six o'clock showing as a small defect in the sphincter

left and comes to an external opening on the left lateral aspect of the anal canal. The tract at six o'clock (Figure $1[B]$ ) runs transphincteric before turning anteriorly and joining with the other tract.

\section{CASE 2}

A 49-year-old woman with colonic Crohn disease treated with corticosteroid only was referred for investigation of increased perianal pain and discharge. Transperineal ultrasound (Figure 2, top and bottom panels) was performed and demonstrated a fistula arising from the anterior wall of the anal canal between 12 o'clock and one o'clock (Figure 2, top panel). The internal opening is broad; from this, there is a hypoechoic tract-like area that runs directly anterior into the vagina.

\section{DISCUSSION}

Transperineal ultrasound for the assessment of perianal Crohn disease was first described by Stewart et al (7) in a cohort of 54 patients being investigated for perianal inflammatory disease. Regular convex, highfrequency, high-resolution linear probes were used. All patients had perianal pathology identified at ultrasound, and 49 had perianal fistulas (intersphincteric, transphincteric and extrasphincteric) or sinuses, of whom 30 underwent surgical intervention and validation of ultrasonographic findings. Of these, 26 patients had perianal fistulas and/or sinus tracts confirmed in the exact anatomical location and course accurately identified on preoperative sonography. Although the location and course of the fistula was confirmed surgically in three patients, the internal opening could not be seen. In one patient, a high perirectal internal opening was not detected on ultrasound but observed at the time of surgery, although the course of the fistula tract was correctly identified on ultrasound (7). The study found transperineal ultrasound to be an accurate and painless technique for the assessment of perianal inflammatory disease and recommended implementing transperineal sonography as a routine sonographic procedure for the evaluation of these patients.

These findings were reproduced in a larger cohort by Mallouhi et al (10). In this study, involving 87 patients with suspected perianal inflammatory disease, transperineal ultrasound performed well in the diagnosis (area under the curve $[\mathrm{r}]=0.85 ; \mathrm{P}<0.001$ ) and characterization $(r=0.65 ; \mathrm{P}<0.001)$ of disease when compared with surgical findings. For the detection of perianal fistulas and abscesses, sensitivity and specificity of transperineal ultrasound ranged from $94 \%$ to $100 \%$ (10). A smaller study involving 25 patients by Wedemeyer et al (11) confirmed high sensitivity and specificity of transperineal ultrasound, when compared with pelvic MRI, for the diagnosis and characterization perianal fistulas and/or abscesses with excellent agreement between the two imaging methods (kappa $>0.83$ ). Comparison of transperineal
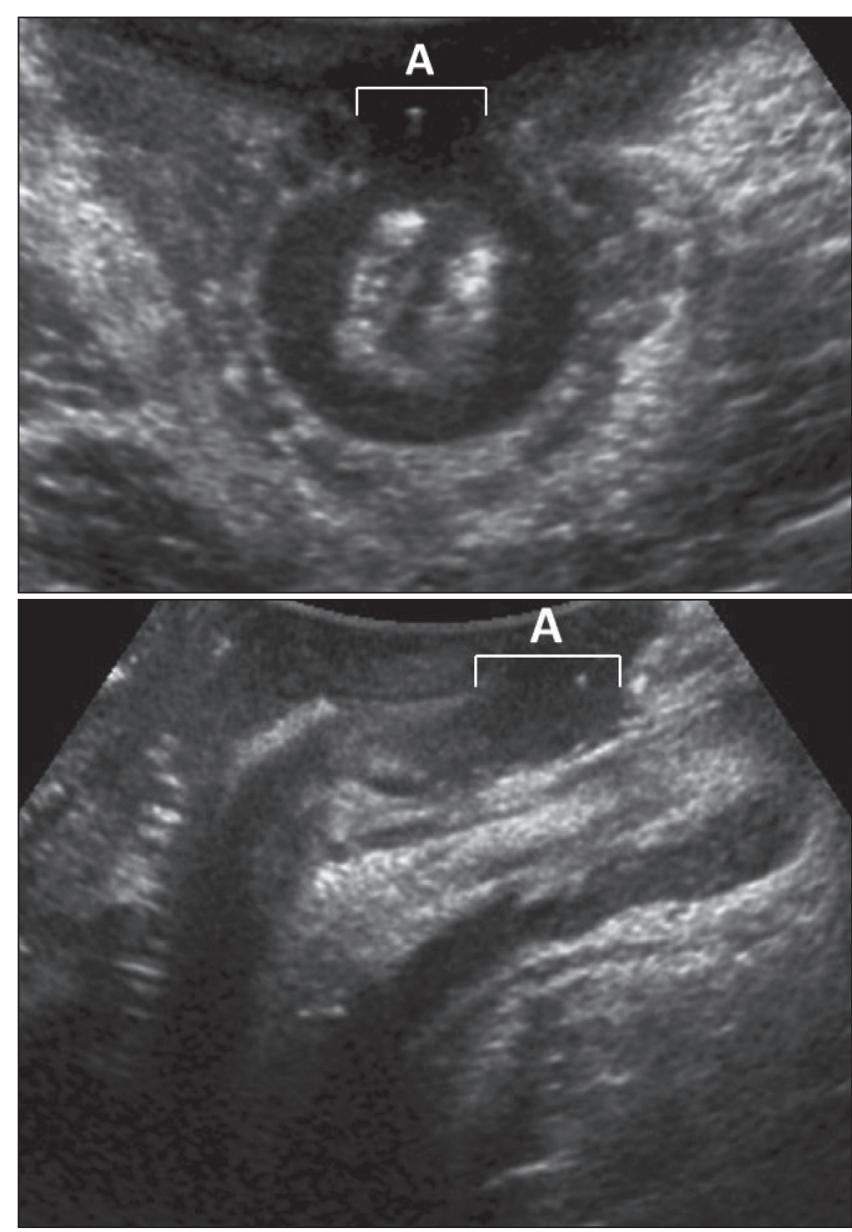

Figure 2) Top panel Transverse view of the anal canal demonstrating the rectovaginal fistula in the 12 o'clock to one o'clock position (A). Bottom panel Sagittal view of the anal canal and vagina. Bracket A shows gas-filled fistula extending from the lumen of the anal canal to the posterior vaginal wall. In both images, the fistula is broad and appears black. A tiny punctate echogenicity within the fistula is a gas bubble

ultrasound and endoanal ultrasound was performed in a study involving 46 patients with perianal Crohn disease by Maconi et al (9). In this study, transperineal ultrasound was accurate for diagnosis and classification of perianal fistulas and/or abscesses, with a sensitivity of $84.9 \%$.

The benefits of transperineal ultrasound are clear. The technique is simple, painless, inexpensive and can be performed in real-time in an outpatient clinic setting or in a radiology department. It is accurate, correlates well with surgical findings and performs well against established methods for perianal imaging including endoanal ultrasound and pelvic MRI. The relative simplicity of the technique and lack of patient preparation required lends itself to point-of-care testing as part of a complete physical assessment in the outpatient clinic setting, enabling prompt clinical decision making. However, despite this, transperineal ultrasound is performed routinely at only a small number of centres worldwide. A possible explanation for this may be the steep learning curve needed to establish proficiency in scanning and interpretation, and the limited opportunities for training. While there are no published guidelines regarding the number of scans or time required to establish proficiency, it has been suggested that competent ultrasonographers will achieve competency in 12 months (7).

DISCLOSURES: The authors have no financial disclosures or conflicts of interest to declare. 


\section{CONCLUSION}

Transperineal ultrasound yields high detection rates, and comprehensive and accurate assessment of perianal fisulas and their complications in patients with Crohn disease. Complex perianal disease requires urgent, even emergent assessment. Although pelvic MRI is currently considered to be the modality of choice for evaluating patients with perianal Crohn disease, transperineal ultrasound has many advantages including lower cost, high patient tolerance, timely access and easy repeatability. Performed by appropriately skilled operators, point-of-care transperineal ultrasound in an outpatient clinic setting offers the possibility of prompt and informed clinical decision making. This technique is currently underappreciated and underused by gastroenterologists and radiologists, despite being first described $>10$ years ago as an efficient and accurate diagnostic tool in the investigation and characterization of perianal Crohn disease.

\section{REFERENCES}

1. Sandborn WJ, Fazio VW, Feagan BG, et al. AGA technical review on perianal Crohn's disease. Gastroenterology 2003;125:1508-30.

2. Mahadev S, Young JM, Selby W, et al. Quality of life in perianal Crohn's disease: What do patients consider important? Dis Colon Rectum 2011;54:579-85.

3. Sands BE, Anderson FH, Bernstein CN, et al. Infliximab maintenance therapy for fistulizing Crohn's disease. N Engl J Med 2004;350:876-85.
4. Van Assche G, Vanbeckevoort D, Bielen D, et al. Magnetic resonance imaging of the effects of infliximab on perianal fistulizing Crohn's disease. Am J Gastroenterol 2003;98:332-9.

5. Kleinubing $\mathrm{H}$ Jr, Jannini JF, Malafaia $\mathrm{O}$, et al. Transperineal ultrasonography: New method to image the anorectal region. Dis Colon Rectum 2000;43:1572-4.

6. Rubens DJ, Strang JG, Bogineni-Misra S, et al. Transperineal sonography of the rectum: Anatomy and pathology revealed by sonography compared with CT and MR imaging. AJR Am J Roentgenol 1998;170:637-42.

7. Stewart LK, McGee J, Wilson SR. Transperineal and transvaginal sonography of perianal inflammatory disease. AJR Am J Roentgenol 2001;177:627-32.

8. Rasul I, Wilson SR, MacRae H, et al. Clinical and radiological responses after infliximab treatment for perianal fistulizing Crohn's disease. Am J Gastroenterol 2004;99:82-8.

9. Maconi G, Ardizzone S, Greco S, et al. Transperineal ultrasound in the detection of perianal and rectovaginal fistulae in Crohn's disease. Am J Gastroenterol 2007;102:2214-9.

10. Mallouhi A, Bonatti H, Peer S, et al. Detection and characterization of perianal inflammatory disease: Accuracy of transperineal combined gray scale and color Doppler sonography. J Ultrasound Med 2004;23:19-27.

11. Wedemeyer J, Kirchhoff T, Sellge G, et al. Transcutaneous perianal sonography: A sensitive method for the detection of perianal inflammatory lesions in Crohn's disease. World J Gastroenterol 2004;10:2859-63. 


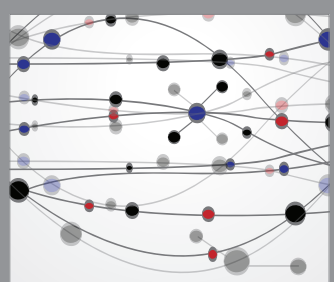

The Scientific World Journal
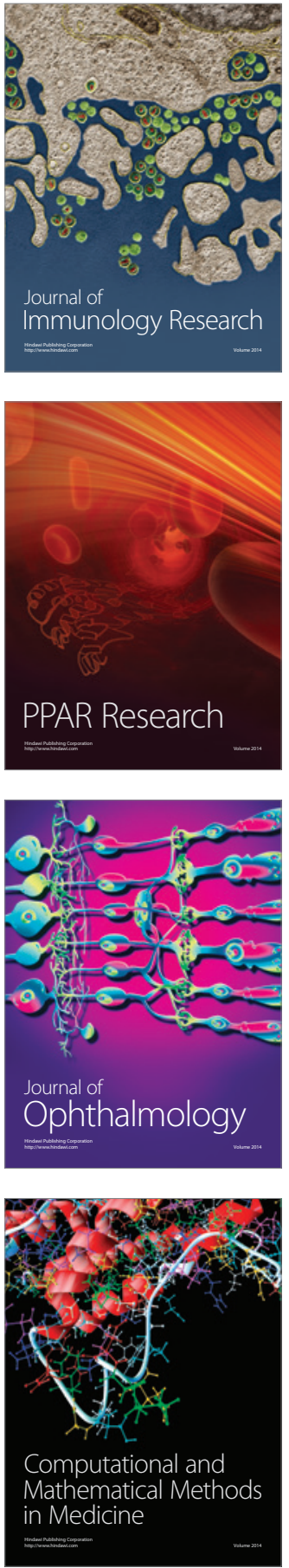

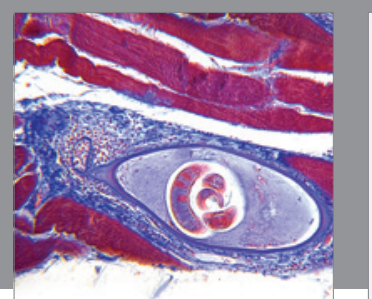

Gastroenterology Research and Practice

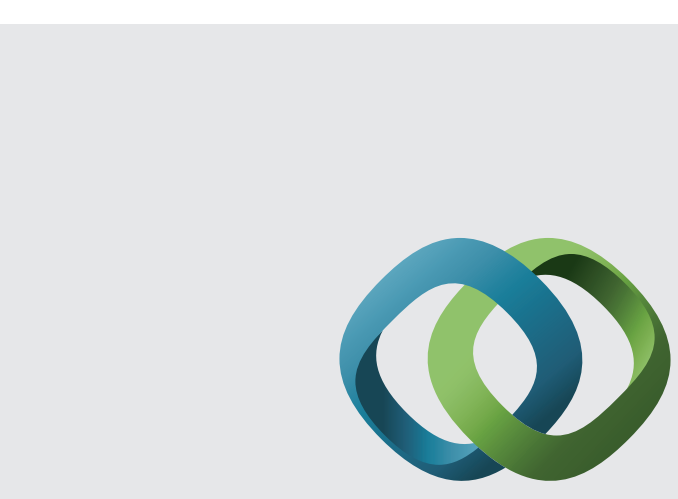

\section{Hindawi}

Submit your manuscripts at

http://www.hindawi.com
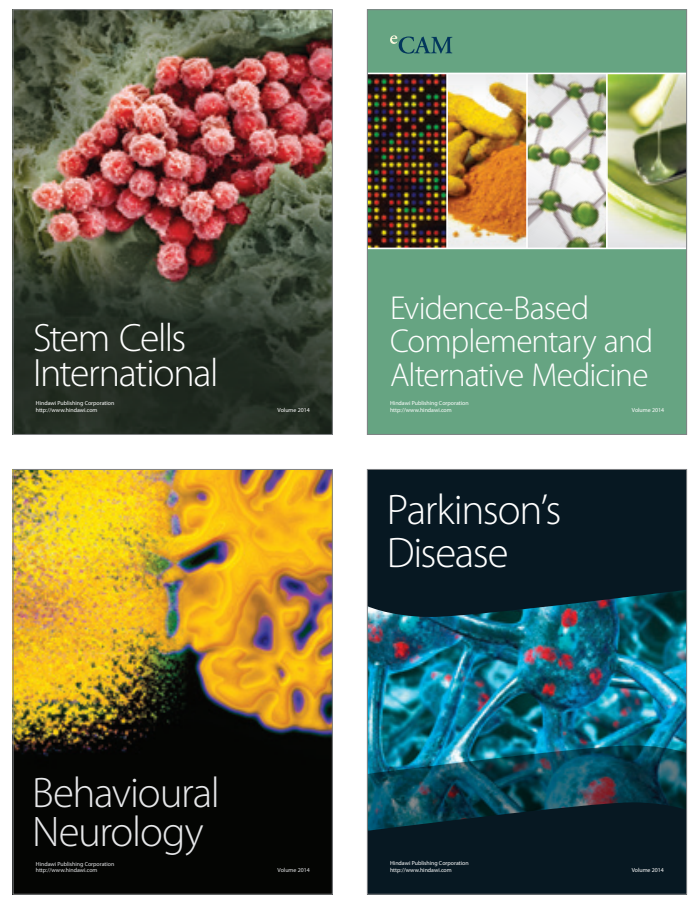
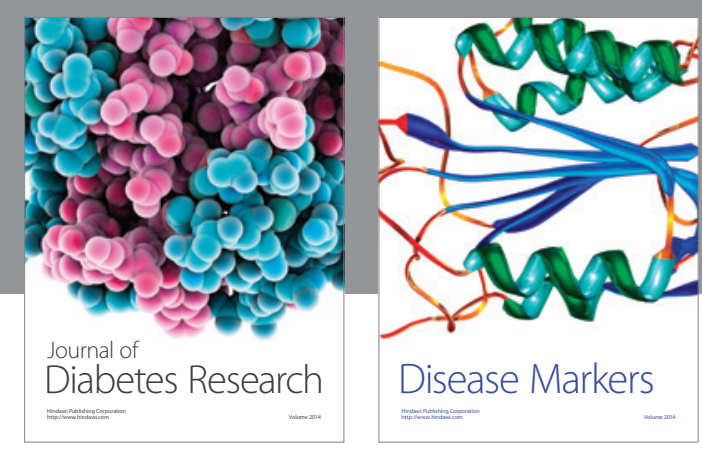

Disease Markers
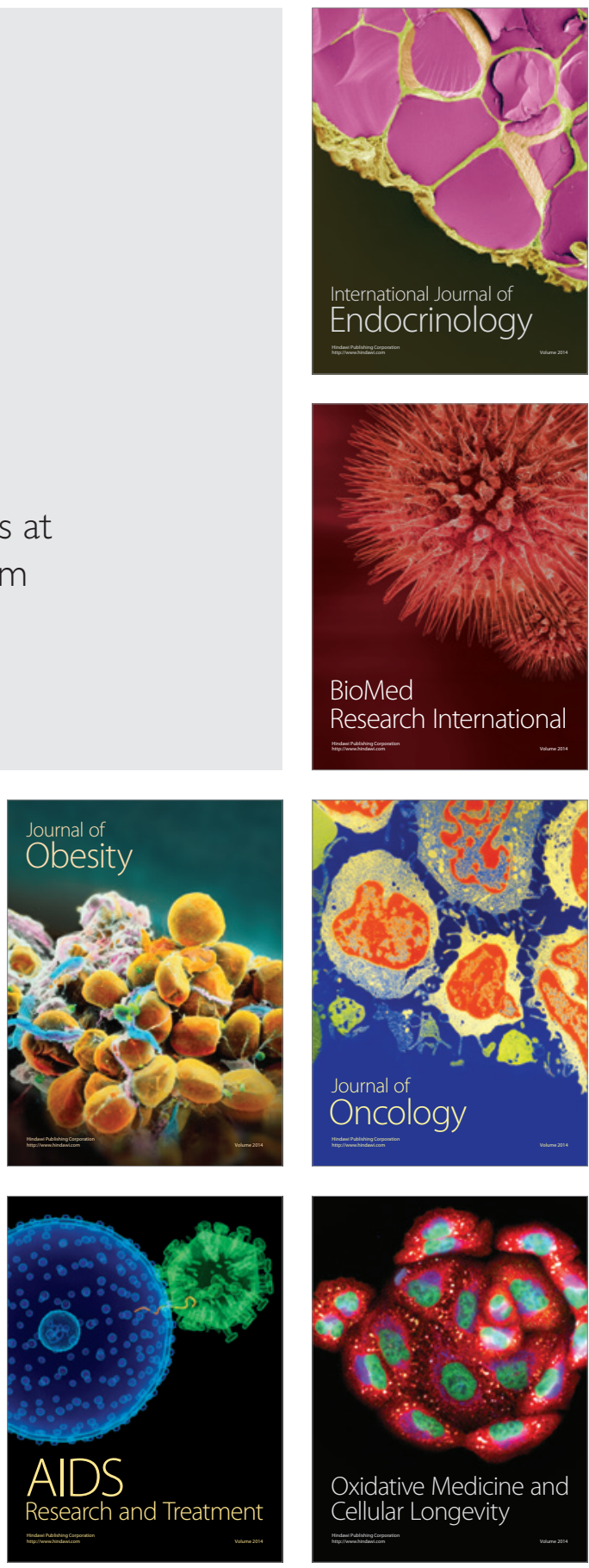